\title{
LA CRÍTICA ES FÁCIL, PERO EL ARTE ES DIFÍCIL*
}

\author{
François Fédier
}

Filósofo

\begin{abstract}
RESUMEN: Analizando el proverbio con que se titula este ensayo, su autor observa que la práctica de un arte requiere que el artista realice también una labor crítica. Ahora bien, el proceso no sería inverso; es decir, el discurso sobre el arte no puede convertirse en arte. De esta manera, el proverbio cumple una primera función de modestia y una segunda, de salvaguardia.

Palabras clave: arte, crítica, Baudelaire.

\section{CRITICISM IS EASY, BUT ART IS HARD}

ABSTRACT: The author analyses the proverb that forms this essay's title and observes that the practice of an art also requires the artist to perform a critical labour. The process does not work the other way around: a discourse on art cannot become art. Thus, the proverb fulfills a twofold function, firstly as an inducement to modesty, and secondly as a safeguard.
\end{abstract}

KEYwords: art, criticism, Baudelaire.

FrançoIs FÉdier. Filósofo francés. Ha sido discípulo de Jean Beaufret y Martin Heidegger. Está encargado de la publicación de la Edición integral (Gesamtausgabe) de este último en la Editorial Gallimard de París. Autor también de numerosos libros, tales como Regarder Voir, Entendre Heidegger et autres exercices d'écoute y Voz del amigo (Santiago: UDP, 2017).

* Traducción de Jorge Acevedo Guerra, profesor titular de filosofía en la Universidad de Chile. Texto publicado originalmente en L'art en liberté (París: Pocket, 2006): 285-292. A menos que se indique otra cosa, lo que va entre corchetes [ ] pertenece al traductor. 
66 a crítica es fácil, pero el arte es difícil”. Estamos en presencia L de una suerte de proverbio del que es bueno que nos recordemos siempre que nos arriesgamos a olvidar una cosa: somos espectadores, auditores o lectores. Como tales, estamos en la confortable situación de quien no hace nada $\mathrm{y}$, sin embargo, evalúa y distribuye censuras y elogios con la entera libertad que confiere el privilegio de ser el público. Dicho de otra manera, esta sentencia llama al público a una mayor modestia frente a los creadores.

Parece, en efecto, que entre el creador y el simple espectador no hay una medida común: uno "hace" algo, mientras que el otro simplemente "habla de ello". Ya los antiguos griegos diferenciaban $\lambda$ ó $\gamma \circ \varsigma$ [lógos] de épyov [érgon], destacando la diferencia que separa — como todavía lo decimos - "lo que digo" de "lo que hago".

Pero no debemos olvidar tampoco que la verdadera relación entre la crítica y el artista no es solamente aquella en que el decir es enteramente desvalorizado respecto del hacer. En efecto, es necesario comprender que todo arte, siendo manifestación, llama constitutivamente a propósito de ella a una estimación. Dicho de otra manera, la imagen del artista enteramente desconectado de todo público es falsa: todo artista se dirige a sus contemporáneos (e, inclusive, da lugar a la contemporaneidad). Cézanne se aislaba tan poco que durante toda la vida intentó exponer en los salones oficiales. Cabe la posibilidad de que un artista más aristocrático desdeñe abiertamente al público mediocre de su tiempo; ${ }^{1}$ en realidad, es para dirigirse a un público informado, que sabe juzgar; por tanto, a un público crítico.

Así, la crítica deja de ser exterior al arte, porque el arte se dirige a hombres que saben reconocer el arte cuando se manifiesta. Si deja de ser exterior al arte, ¿cómo puede ser fácil mientras que el arte es difícil?

Pero no vayamos demasiado rápido. ¿Cómo comprender que la crítica sea fácil? Si es fácil, es que su trabajo es mínimo. Mientras que el artista debe producir la licitud [loyauté] ${ }^{2}$ de una obra (una licitud a la vez universal —es la libertad misma - y singular — es la necesidad XVIII.

${ }^{1}$ La existencia de un público mediocre es un fenómeno reciente; data del siglo

${ }^{2}$ Es necesario entender loyauté como un doblete de legalité [legalidad]. [La palabra "doblete" hay que entenderla aquí en el sentido lingüístico del término.] 
misma de toda obra-), el crítico no tiene más que reconocerla, descubrirla, o bien mostrar que en ella no hay licitud.

O quizás, "crítica" no tiene sino un sentido limitado o inclusive poco amistoso, el de hablar mal [dire du mal]. En este sentido, criticar no tiene ningún interés - es perfectamente evidente que hablar mal es fácil-. Es nuestra inclinación natural, aquella de donde surge siempre, con una sorprendente facilidad, la proclividad a poner objeciones.

¿Por qué, pues, sería más fácil reconocer la licitud de una obra o su ausencia que crearla o ponerla en obra?

Porque está dada. Aquí hablamos de una crítica esencialmente positiva, que abre la posibilidad de ver la doble licitud. Los ejemplos abundan. Tomemos uno caro a Jean Beaufret: la noción crítica de "estructura diáfana" para mostrar la arquitectura gótica. Ha sido el historiador del arte Hans Jantzen — por quien Heidegger tenía una genuina estima - el que ha desarrollado la idea de "estructura diáfana". ${ }^{3}$ Es una estructura del espacio litúrgico. En la arquitectura gótica, explica Jantzen, el fenómeno peculiar es la aparición o la estructuración del espacio litúrgico en diafanidad. Y, en efecto, quién puede permanecer ciego al espíritu translúcido de las catedrales góticas en las que el espacio está hecho para dejar jugar la luz (no toda la luz, como entre nosotros con las torres de cristal), aunque sólo una modulación de la luz, desde lo oscuro hasta lo más brillante, e inclusive en el reflejo de los colores provocado por los vitrales. Es un arte completamente consciente. Se lo puede mostrar a través de la simbólica de los colores $\mathrm{y}$, más generalmente aún, si se observa que el vitral, entre otros, es símbolo de Cristo: permite la encarnación de la luz en colores.

Jantzen ofrece una iluminación extraordinariamente pertinente sobre el arte gótico. Para conseguirla hubo que tener un buen ojo, y no perder de vista el espacio gótico mismo, tal como fue hecho por los arquitectos de la Edad Media. Hacer es, así, más difícil que ver. Comparada con el arte, la crítica es, así, más fácil.

${ }^{3}$ Ver Hans Jantzen, "Structure interne de l'église gothique", trad. de Julien Hervier, en L'Information d'histoire de l'art (Éditions Baillière, 1972), 103-112. [Ver J. Beaufret, "En chemin avec Heidegger", en Dialogue avec Heidegger, vol. IV (París: Les Éditions de Minuit, 1985), 122 y ss. Hans Jantzen, La arquitectura gótica, trad. de José María Coco Ferraris y ed. de Juan Manuel Borthagara e Iván Hernández Larguía (Buenos Aires: Eds. Nueva Visión, 1985), 82 y ss. Ahí Jantzen refiere a la conferencia que dio por resultado el escrito citado por Fédier]. 
Ella es, pues, aún exterior al arte —en una exterioridad que se puede representar temporalmente como sigue: la crítica llega después de la obra- - Y es la anterioridad de la obra respecto de la crítica lo que explica por qué la crítica es fácil.

En este momento es necesario comenzar a agudizar la mirada. Hemos notado más arriba que el artista, produciendo una obra, abre una posibilidad de contemporaneidad. Esta instauración no tendría ningún sentido si el cara a cara frente a la obra no pudiera tener lugar en esta contemporaneidad: si escucho una sonata de Beethoven, estoy en el tiempo de Beethoven. ${ }^{4}$

Hablar en este momento de crítica ¿tiene aún un sentido? Solamente si podemos mostrar que hay una crítica de la obra en cada poeta. Es lo que enseña reiteradamente la historia de la poesía. Inclusive si se lo pudiera exponer a propósito de poetas atípicos (en los que no hay ningún arte poético), esto se mantiene en no menos medida que en los más grandes - Píndaro, Shakespeare, Hölderlin, para no citar sino a los líricos-; todos los poetas son de un rigor métrico muy sorprendente, lo que podríamos ilustrar diciendo que la ciencia de la métrica, en los poetas, es análoga a la manera en que los arquitectos góticos llegaban a hacer aparecer su espacio gracias a la modulación de la luz.

La poesía misma es pura manifestación —en griego: ả $\operatorname{có}_{\varphi \alpha v \sigma 1 \zeta}$ [apóphansis], donde póvбis [phánsis] es de la misma raíz que diá-

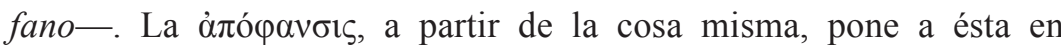
condiciones de mostrarse en completa claridad. ${ }^{5}$ En los poetas, esta cosa es el ritmo. Esto no puede hacerse sin una crítica. Es claro que aquí la palabra no tiene ya ni puede ya tener el sentido corriente. Aquí, "crítica" designa la interioridad misma de la poesía. Leyendo el Dictionnaire étymologique de la langue grecque de Chautraine, descubrimos que крıтós [kritós] corresponde exactamente al certus latino (en el sentido de: "sobre esto, estoy fijado"); pero dejemos la palabra a Baudelaire:

${ }^{4}$ Dicho de otra manera, en el mismo tempo.

5 "El poeta expone el mundo a menor escala", escribe Hölderlin hacia el final de "Notas sobre Antígona". [Ver Friedrich Hölderlin, Ensayos, traducción de Felipe Martínez Marzoa (Pamplona y Madrid: I. Peralta Ediciones / Ed. Ayuso, 1976), 151]. 
Así, el principio de la poesía es, estricta y simplemente, la aspiración humana hacia una belleza superior, y la manifestación de este principio está en un entusiasmo, una excitación del alma - entusiasmo completamente independiente de la pasión, que es la embriaguez del corazón, y de la verdad, que es el pábulo de la razón-. Porque la pasión es natural, demasiado natural para no introducir un tono hiriente, discordante en el dominio de la belleza pura; demasiado familiar y demasiado violenta para no escandalizar a los Deseos puros, a las Melancolías graciosas y a las Desesperaciones nobles que habitan en las regiones sobrenaturales de la poesía. ${ }^{6}$

Se ve aquí a Baudelaire bosquejar la estructura del espacio poético. $^{7}$ Es el espacio donde lo desunido aprende a reconocerse como desunido, es decir, separado de aquello respecto de lo cual, si no, estaría re-unido y formaría una unidad: Las flores del mal —el solo título nos ilustra con toda claridad: si las flores son del mal, la creación entera está rota- Pero si la creación, a través del hombre, se comprende como caída [déchue], tiene la medida para toda redención. "Lo Bello", dice Baudelaire, "no es sino promesa de felicidad". 8 Ahí, el poeta y el crítico se confunden. En un texto sobre Wagner, Baudelaire escribe:

...todos los grandes poetas se convierten naturalmente, fatalmente, en críticos. ${ }^{9}$

${ }^{6}$ Charles Baudelaire, Critique littéraire, en Euvres complètes, t. II (París: Pléiade, 1976), 334. [Ver también Charles Baudelaire, "Nuevas notas sobre Edgar Poe, § IV", en Edgar Allan Poe, traducción de Carmen Santos (Madrid: Ed. Visor, 1989), 106.]

${ }^{7}$ La ảjó $\varphi \alpha v \sigma 1 \varsigma$ es la mostración a partir de la manifestación —es la demostración del ritmo-. Es necesario entender aquí el ritmo como constitución; dicho de otra manera, el ritmo es esencialmente estático, algo estructural. En el pensamiento de Baudelaire, la de-mostración: del Deseo; de la Melancolía; de la Desesperación. El ritmo es la manifestación del tono concordante entre el Deseo, la Melancolía y la Desesperación.

${ }^{8}$ [Charles Baudelaire, "Le peintre de la vie moderne. I. Le beau, la mode et le bonheur", en CEuvres complètes (París: Pléiade, 1954), 884. Charles Baudelaire, "El pintor de la vida moderna. I. Lo bello, la moda y la felicidad", en Salones y otros escritos sobre arte, traducido por Carmen Santos (Madrid: Ed. Visor, 1999), 351.]

${ }^{9}$ Baudelaire, Euvres complètes, t. II, 793. [Euvres complètes (1954), 1059. También Charles Baudelaire, "Richard Wagner y Tannhäuser en París", en El arte romántico, traducción de Carlos Wert (Madrid: Ediciones Felmar, 1977), 242.] 
Como lo precisa en la misma página, esto significa:

ellos quieren razonar su arte, descubrir las leyes oscuras en virtud de las cuales han producido, y obtener de este estudio una serie de preceptos cuya finalidad divina es la infalibilidad en la producción poética.

Entendamos bien a Baudelaire: no se trata de que el artista se ocupe reflexivamente de su obra para descubrir en ella, como datos, las leyes de su producción. El arte no es la naturaleza. Lo que permite existir al arte como arte es la crítica en su sentido original: lo que separa.

Antes de dejar a Baudelaire, escuchemos una última frase. Habla, hacia el final de De l'essence $d u$ rire... del fenómeno que:

entra en la clase de todos los fenómenos artísticos que denotan en el ser humano la existencia de una dualidad permanente, el poder de ser a la vez sí y otro. ${ }^{10}$

Tal es la separación radical. Es claro que aquí la distinción entre crítica y arte se extingue. El poeta es enteramente poeta solamente en el instante en que se alza al conocimiento de las leyes de la poesía. La relación entre crítica y arte se ha invertido: la crítica (o discernimiento) ha llegado a ser principio de la poesía.

¿Hay todavía alguna verdad en el proverbio? Sin duda alguna. Una verdad que, en última instancia, es muy importante alcanzar, porque nos arriesgamos a confundir crítica y arte. Lamentablemente, nuestro tiempo está en la confusión. No solamente recusa que la crítica sea fácil, sino que pretende que la crítica es un arte. Lo esencial ya no es el arte, sino el discurso sobre el arte.

Aquí nuestro proverbio encuentra su misión de salvaguardia [gar$d e-f o u]$. Aunque es necesario no olvidar nuestro logro: todo artista incluye un crítico. Lo que es ilegítimo es lo recíproco. En efecto, ningún crítico que no ha sido sino crítico puede, imparcialmente, ser considerado como un artista. La razón de eso es tan simple como luminosa: lo

${ }^{10}$ Baudelaire Euvres complètes, t. II, 543. [Euvres complètes (1954), 728]. Rimbaud escuchará: "Je est un autre" ["Yo es otro"]. [Ver Charles Baudelaire "De la esencia de la risa...", en Lo cómico y la caricatura, traducción de Carmen Santos (Madrid: Ed. Visor, 1988), 50 y ss.] 
que el crítico ha descubierto se encontraba, antes, en el arte apreciado. Jantzen ha descubierto la estructura diáfana en las catedrales góticas, pero son ellos, los arquitectos, los que la han hecho aparecer, dado que no existía antes de ellos.

La diferencia infranqueable que es necesario aprender a discernir es que el arte es crítico mientras que la crítica no es artística. En ningún caso la crítica puede producir; no puede sino reproducir. En el lenguaje de la contemporaneidad: el artista es al mismo tiempo crítico, dando lugar a la posibilidad de un tiempo de la obra en el que la crítica exterior a la obra puede llegar a ser contemporánea. Pero la crítica sola es incapaz de fundar la contemporaneidad.

Ella es fácil, pero esta vez en el sentido originario del término. En efecto, "fácil" [aisé] es el doblete popular de "adyacente" [adjacent]. ¿Qué quiere decir esto? Lo que es fácil es de alguna manera adyacente, en el sentido de que está al lado de algo hasta tocarlo. La crítica es fácil porque es adyacente al arte. En geometría, los ángulos adyacentes son aquellos que tienen un lado común. La crítica y el arte tienen manifiestamente un lado común, pero el arte produce la obra respecto de la que la crítica no hace sino hablar.

\section{Esquema de una conclusión posible}

Idea general: es curioso el tipo de verdad de los proverbios. En efecto, ellos expresan verdades de sentido común. Ahora bien: lo que caracteriza a este tipo de verdad es que, generalmente, lo que tiene el sentido común tiene igualmente, pero de manera más secreta, mucho más sentido.

Ilustración: la primera función de este proverbio es el llamado a la modestia. La segunda, mucho más profunda (y de tal modo que funda a la primera), es la función de salvaguardia.

Problema particular de la conclusión: iprocuremos no repetir algo que ya ha sido dicho! EP 